\title{
Innovative User Experience Design and Customer Engagement Approaches for Residential Demand Response Programs
}

\author{
Matteo Barsanti ${ }^{1}$, Letizia Garbolino ${ }^{2}$, Muhammad Mansoor ${ }^{1}$, Giulia Realmonte ${ }^{1}$, Rita \\ Zeinoun $^{3}$, Francesco Causone ${ }^{1}$ and Valentina Fabi ${ }^{4}$ \\ ${ }^{1}$ Department of Energy, Politecnico di Milano, via Lambruschini 4, 20156 Milano, Italy \\ ${ }^{2}$ Department of Architecture and Design, Politecnico di Torino, v.le Pier Andrea Mattioli 39 \\ 10125 Torino, Italy \\ ${ }^{3}$ Department of Architecture and Urban Studies, Politecnico di Milano, via Bonardi 3, 20133 \\ Milano, Italy \\ ${ }^{4}$ Department of Energy, Politecnico di Torino, c.so Duca degli Abruzzi 24, 10129 Torino, Italy
}

\begin{abstract}
The increasing share of intermittent sources is making it more difficult to guarantee a real-time balance between demand and supply on the electricity grid. To decrease the dependency from fossil fuel generation, a change in paradigm is required: from supply following demand whenever it occurs to demand following generation when it is available. Demand Response (DR) programs enclose all practices that allow demand to take part in actively managing the grid. According to this perspective, the residential sector hides a huge still unexploited flexibility resource. Therefore, utilities and aggregators need to address weak customer engagement and a lack of regulation in order to employ innovative business models for harnessing residential DR programs potential. Within this paper, some of these challenges are investigated, with the view to improve the design of an appropriate engagement strategy and an incentive scheme to involve residential customers. The innovation consists in the development of a questionnaire as a tool to understand customers' behavior and preferences, so to consequently design customized solutions. Finally, a first order approximation techno-economic analysis is conducted to contextualize the actual incentives for the single customer.
\end{abstract}

Keywords: Experience Design, Customer engagement, Demand Response.

\section{Introduction}

According to the urgent need to decarbonize our economy, new solutions have to be found in order to provide the required flexibility [1] for integrating intermittent renewable power sources, such as solar and wind. Among the new sources of flexibility, Demand Response (DR) is becoming a cost-effective solution, pushed by electrification of transport and heating/cooling sectors and new supporting technologies. 
By definition, DR refers to any change in electrical consumption done by consumers with respect to their usual patterns during peak demand times and in response to electricity price variations over time [2]. These changes in consumption can be caused either by manual operation of customers (i.e. Manual DR) or by a remote control of the loads (i.e. Automated DR). DR should include a form of incentive payments to the final customers, so to trigger their active participation [3].

Considering the status of DR in European electricity market [4], it can be noticed that, while at industrial and commercial level DR practices encounter an appropriate legal framework (e.g. UK, Switzerland, Belgium and France), at residential level they are still in test phase. Nevertheless, the majority of theoretical demand response potential lies with residential consumers, hindered by low consumer engagement with energy-related activities, and a lack of regulation specifically designed for this customer segment. In recent years, several reports have studied evidences of consumer engagement for residential DR in UK through surveys, trials and pilot schemes [5-7]. Three critical elements to unlock the potential of DR are the maximization of value proposition, consumer awareness about their energy choices and the risk reduction of negative influences [8], but scientific evidences about customer engagement and economic potential of DR programs are still limited.

The focus of this paper is to investigate some of the challenges utilities and aggregators need to address in order to harness the potential coming from manual and automated load shifting at household level. In particular, it has been depicted a general procedure to facilitate the design of an appropriate engagement strategy and incentive scheme to involve residential customers and offer this flexibility as a service on the electricity market. The innovation consists in the development of a questionnaire as a tool to understand customers' behavior and preferences, so to consequently design customized solutions for DR programs. The questionnaire was rolled out in Italy to perform a first validation, by considering respondents' feedbacks and consistency of the results. At the same time, a step-based framework has been defined to develop DR programs in the residential market, so to involve progressively more and more people.

Section 2 describes the methodology adopted to prepare the questionnaire and the engagement strategies, together with the procedure applied for the techno-economic assessment of residential DR. Section 3 describes the questionnaire development and the results obtained after the first roll-out. Finally, section 4 contains the detailed techno-economic analysis followed by the conclusion in section 5 .

\section{Nomenclature}

\begin{tabular}{|ll|}
\hline DCE & Discrete Choice Experiment \\
DESWH & Domestic Electric Storage Water Heater \\
DR & Demand Response \\
DUoS & Distribution Use of System \\
FFR & Firm Frequency Response \\
STOR & Short Term Operating Reserve \\
TNUoS & Transmission Network Use of System \\
WTP & Willingness To Pay \\
\hline
\end{tabular}




\section{Methodology}

One of the main problems of energy engagement campaigns directed towards residential customers are the high drop-out rates, as people do not perceive benefits or a clear incentive to change their daily habits. In order to avoid this, a step-based approach is expected to have a twofold benefit. On the one hand, each step is simplified, and customers can better embrace the change, feeling it less demanding or disruptive; on the other hand, it allows to update the following steps according to new technologies, trends and local requirements.

Customers are involved step by step, starting with an extensive customer engagement phase, followed by the actual DR program. Despite being interlocked and sharing the main actors, each of the progressive steps will have a specific business model and value proposition. A brief description of the steps is provided below:

1. User Experience Design. The environment where the program will be implemented is analyzed. Customer characteristics and preferences are outlined through a questionnaire, in order to tailor the services and the communication strategies.

2. Customer Engagement and Awareness. Customer activity and community involvement are emphasized. Services that are offered are not limited to energyrelated ones, to further stimulate interest of customers through additional drivers.

3. DR Programs. Once residential customers have understood the value of being "active", they can contribute to the grid management through load shifting. DR can be implemented both manually and automatically.

\subsection{Questionnaire and Engagement Strategies}

A questionnaire has been developed to evaluate the preferences of end-users and their willingness to pay for a number of energy-related services. The questionnaire survey is considered as a tool for identifying customer segments and tuning the service offering accordingly. Within the questionnaire, a Discrete Choice Experiment (DCE) has been selected as a quantitative technique to investigate customers preferences over different service attributes based on a marginal valuation method. DCEs allow to assess the Willingness To Pay (WTP) for having the preferred attribute included in a product or service [9]. With respect to the methodologies where attributes are ranked or rated by individuals (i.e. conjoint analysis), stated preference methods (i.e. choice experiments) are closer to the real-life situation of any shopping experience, where the customer is asked to make a choice among products with marginal substitutions. Presenting attributes as embedded in a service, results are less affected by strategic answering (i.e. moral arguments), indicating which attributes the respondents are more sensitive to [11].

Customer engagement strategies are implemented via communication channels (i.e. mobile application, web portal) where end-users interact with energy providers and manage their energy-related services. "Idea flow" and gamification strategies play a major role in engaging users on the long run. Idea flow [11] refers to the propagation of behaviors and beliefs through a social network by means of social learning and 
social pressure: people are inclined to take action according to their peers' behavior. In addition, gamification and individual rewards effectively stimulate users, and prevent the program from being considered as a boring duty. Competition among peers triggers these strategies, hence reward schemes are based both on individual achievement and comparative data, and saving challenges are set up.

Despite the important role of social pressure in customer engagement, the economic dimension remains the dominant one. In this regard, a techno-economic preanalysis was developed. The aim is to outline critical aspects that may affect manual and automated DR economic potential at residential level now and in the future, rather than an accurate estimation of their present value.

The approach applied to both types of DR program, can be summarized as follows: first, determine household appliances that are able to provide load flexibility and their capacity; second, understand which application each type of demand-side management may be more suited to; once the DR use is selected, identify the economic unitary value obtained by selling the flexibility as a market product or by increasing operational saving; then, based on these data, estimate the overall potential revenues, that eventually must be compared with the expected costs of the programs.

\section{Questionnaire and Results}

The choice experiment included in the questionnaire has been designed following a case study where interviewees select their preferred scenarios for landscape development [12]. The attributes included in each scenario represent the main features of a product or service and its price: each of them can have different levels representing the various states of that feature. Analyzing results, it can be identified which attributes levels the users are more inclined to pay for. The software Gretl has been used to run a multinomial logit model and provide coefficients for the WTP calculation. These coefficients are then employed in the equation (1) defining the WTP as "minus the ratio between the estimate of the coefficient for the attribute of interest and the tax coefficient" $[12,13]$. The resulting WTP values represent the additional (positive or negative) amount of money the customers are willing to pay for having one specific feature in the service, with respect to a base level.

$$
W T A_{a}=-\left(\frac{\beta_{a}}{\beta_{\text {interest rate }}}\right)
$$

\subsection{Questionnaire Development and Description}

Our questionnaire "Evaluation of preferences for Monitoring Services and Management of Electricity Consumption in residential buildings" has three main objectives: identify customer segments, investigate user awareness, learn the most valued features. Consequently, the survey has been divided in multiple sections: 
- Characteristics of the User, including questions about age, gender, educational level, number of household members, income, dwelling type, size and construction year, energy consumption, and use of the main electric appliances.

- Energy Awareness, including open and multi-choice questions about climate change, pollution and energy waste, while investigating the actions performed to save energy in their houses.

- Dual-choice Tasks, where the interviewee has to choose between packages with different services and prices. 22 packages - coupled into 11 choice tasks - are built upon combinations of different levels of the 5 selected attributes, according to Table 1. The combination process, an "orthogonal design" by IBM SPSS software, allows getting meaningful results through a limited number of combinations [12].

Each package includes one level from each attribute. The base monthly fee relates to similar services offered by European companies. On top of that, the fee includes the lease of devices, where present within the offer.

The questionnaire was spread out as an online form and sponsored by word-ofmouth. A first group of 30 respondents provided direct feedback about the intelligibility of the survey. In parallel, the overall structure was analyzed by an expert, highlighting specific issues. The questionnaire was adjusted according to these feedbacks and then spread out to a larger group of people living in Piemonte and Lombardia (Northern Italy). The achieved number of respondents was 83.

Table 1. Dual-choice tasks: attributes levels

\begin{tabular}{|c|c|c|c|}
\hline Attribute & Level A & Level B & Level C \\
\hline User Interface & $\begin{array}{c}\text { Notifications via SMS; services } \\
\text { management via account on } \\
\text { website }\end{array}$ & $\begin{array}{c}\text { Notifications and services man- } \\
\text { agement via In-Home Display }\end{array}$ & $\begin{array}{c}\text { Notifications and services } \\
\text { management via mobile } \\
\text { application }\end{array}$ \\
\hline Base Service & $\begin{array}{c}\text { Reports on historical consump- } \\
\text { tion data and real-time feedback }\end{array}$ & $\begin{array}{c}\text { Level A + short-term advice about } \\
\text { behavioral change }\end{array}$ & $\begin{array}{c}\text { Level B + automated } \\
\text { control of some electric } \\
\text { appliances }\end{array}$ \\
\hline $\begin{array}{c}\text { Additional } \\
\text { Rewards }\end{array}$ & $\begin{array}{c}\text { Gamification and data compari- } \\
\text { son within a virtual community }\end{array}$ & $\begin{array}{c}\text { Inefficiency detection of house- } \\
\text { hold electric appliances }\end{array}$ & $\begin{array}{c}\text { Long-term advice (e.g. } \\
\text { retrofit measures, applianc- } \\
\text { es replacement) }\end{array}$ \\
\hline Rewards & $\begin{array}{c}\text { Bonus for public transport and } \\
\text { shared sustainable mobility }\end{array}$ & $\begin{array}{c}\text { Discounts on products purchased } \\
\text { via approved platforms or sellers }\end{array}$ & $\begin{array}{c}\text { Discounts on the energy } \\
\text { bill }\end{array}$ \\
\hline Monthly Fee & $5 €$ & $11 €$ & $16 €$ \\
\hline
\end{tabular}

\subsection{Questionnaire Results}

Because of the small and to some extent uneven group of respondents (i.e. age distribution), the survey cannot be considered an accurate market analysis. However, some considerations about the market segment and the questionnaire potential can be discussed. Respondent's age, Household income, and Household members are set as the clustering criteria, and three values (respectively 29 years old, 25000€, 2 people) are chosen for splitting the respondents' group into categories. These clusters are employed when representing the electric appliances use patterns (Fig. 1) and the WTP (Fig. 2). From these charts, market strategies insights can be derived. For instance, the 
clusters showing a peak of appliances use in the evening (younger respondents, higher-income households, smaller households) are those with a stronger preference for appliances' automated control. Smaller households, whose appliances-use pattern suggest the house in mostly empty at daytime, are those showing the lowest preference towards a fixed In-Home-Device.
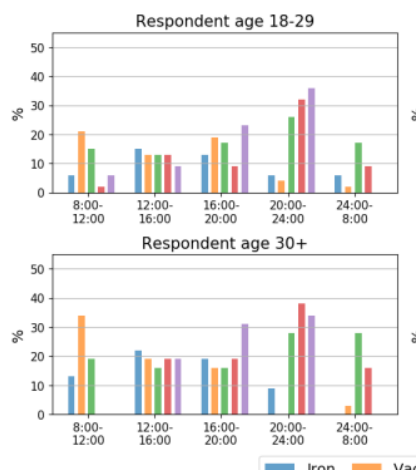

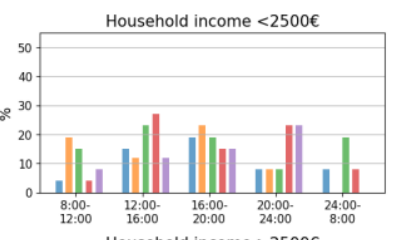

Household income $>2500 €$

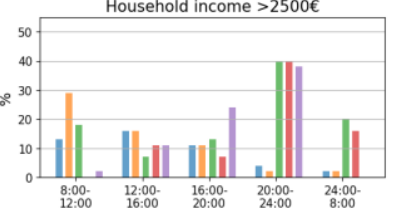

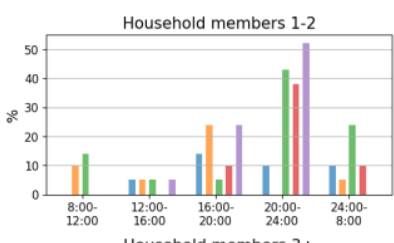

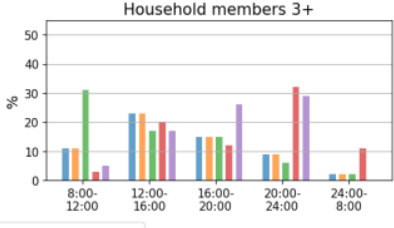

Fig. 1. Respondents' electric appliances use pattern by cluster

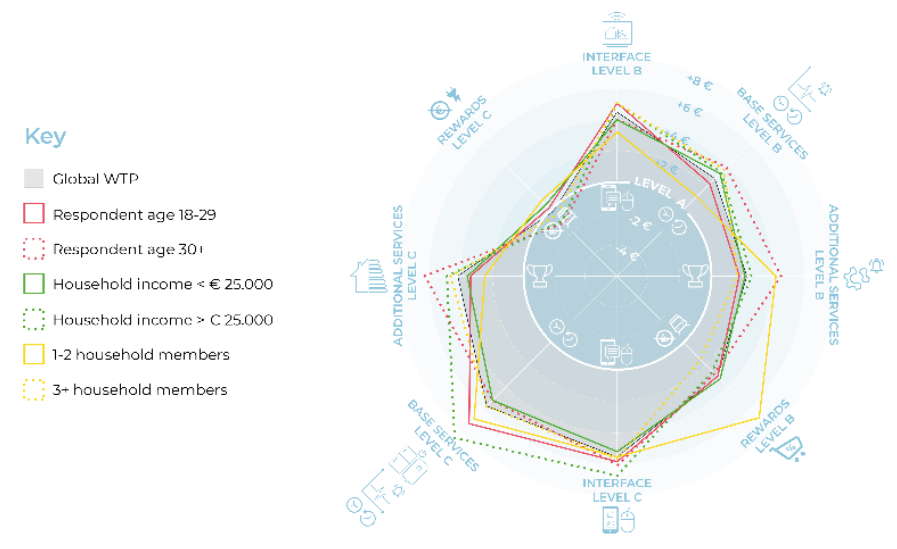

Fig. 2. Respondents' WTP represented globally and by cluster

\section{Techno-economic Analysis}

This section aims to generally evaluate whether manual and automated DR programs are economically self-sustainable, highlighting the main assumptions and uncertainties behind the analysis. No presumptions about value accuracy are meant, so that the results are to be considered limited to their order of magnitude. 


\subsection{DR Sources and Uses}

Demand flexibility can be provided either when the appliance has some degree of energy storage or when the consumers are willing to postpone its usage [14]. A highresolution stochastic demand model calibrated with UK data and statistics, CREST [15], has been used to determine daily residential load profiles and to assess load capacity. For our analysis, the reference is a typical three-residents UK terraced household. Load demand has been simulated for four representative days of the year.

The flexibility extent for each appliance is strongly dependent on dwellers' habits and load patterns, hence it is important to use real data from a similar context to the one under analysis. In our case, field evidence from past trials has been used to determine the response that can be achieved with different DR programs [5,16,17], see Table 2.

Table 2. DR uses and resources parameters. s: summer; n: not summer; y: yearly

\begin{tabular}{|c|c|c|c|c|c|c|c|c|c|}
\hline Use & Price & $\begin{array}{c}\text { DR use time } \\
\text { window }\end{array}$ & $\begin{array}{c}\text { Total } \\
\text { Load }\end{array}$ & Fridge & $\begin{array}{c}\text { Dish } \\
\text { Washer }\end{array}$ & Dryer & $\begin{array}{c}\text { Washing } \\
\text { Machine }\end{array}$ & $\begin{array}{c}\text { Water } \\
\text { heater }\end{array}$ & $\begin{array}{c}\text { Heat } \\
\text { pump }\end{array}$ \\
\hline $\begin{array}{c}\text { Wholesale price } \\
\text { spread }\end{array}$ & $\begin{array}{c}50 \\
\text { f/MWh }\end{array}$ & daily & $6-15 \%$ & - & - & - & - & - & - \\
\hline $\begin{array}{c}\text { Cash-out imbal- } \\
\text { ance }\end{array}$ & $\begin{array}{c}40 \\
\text { f/MWh }\end{array}$ & daily & $6-15 \%$ & - & - & - & - & - & - \\
\hline $\begin{array}{c}\text { Short Term } \\
\text { Operating } \\
\text { Reserve (STOR) }\end{array}$ & $\begin{array}{c}15 \\
\text { f/kW/y }\end{array}$ & $\begin{array}{c}7: 00-14: 00 \mathrm{~s} \\
10: 00-14: 00 \mathrm{n} \\
17: 00-23: 00 \mathrm{y}\end{array}$ & - & $0 \%$ & $78 \%$ & $78 \%$ & $78 \%$ & $50 \%$ & $50 \%$ \\
\hline $\begin{array}{c}\text { Firm Frequency } \\
\text { Response (FFR) }\end{array}$ & $\begin{array}{c}50 \\
\text { f/kW/y }\end{array}$ & daily & - & $100 \%$ & $78 \%$ & $78 \%$ & $78 \%$ & $100 \%$ & $100 \%$ \\
\hline $\begin{array}{c}\text { Transmission } \\
\text { Network Use of } \\
\text { System (TNUoS) }\end{array}$ & $\begin{array}{c}46 \\
\mathrm{f} / \mathrm{kW} / \mathrm{y}\end{array}$ & $17: 00-18: 00 \mathrm{w}$ & - & $0 \%$ & $78 \%$ & $78 \%$ & $78 \%$ & $100 \%$ & $100 \%$ \\
\hline $\begin{array}{c}\text { Distribution Use } \\
\text { of System (DUOS) }\end{array}$ & $\begin{array}{c}26 \\
\text { f/kW/y }\end{array}$ & $\begin{array}{c}11: 00-14: 00 \mathrm{~s} \\
16: 00-19: 00 \mathrm{w}\end{array}$ & - & $0 \%$ & $78 \%$ & $78 \%$ & $78 \%$ & $33 \%$ & $33 \%$ \\
\hline
\end{tabular}

In order to couple flexibility sources with their appropriate use, the framework developed in [14] has been readapted and improved for our purposes (Fig. 3). This framework selects among all the possible DR uses (represented by different colored field in the chart) only the ones whose technical requirements (i.e. notice period, duration and frequency, represented by the different axis) can be guaranteed by the source (different class of appliances). Events duration and notice period are the main requirements for direct load control practices (i.e. automated DR), because end-users are not directly involved. Differently, in manual DR programs events regularity acquires importance, affecting the response rate in the short and long-run [18].

A reasonable assumption is to consider that the conditions (prices and requirements) imposed by the current UK regulation for industrial and commercial DR programs will be kept unchanged also for residential applications, at least in the shortterm scenario. It is possible that over the coming years, new regulatory arrangements (e.g. network charges) could lead to different requirements and prices for DR. 


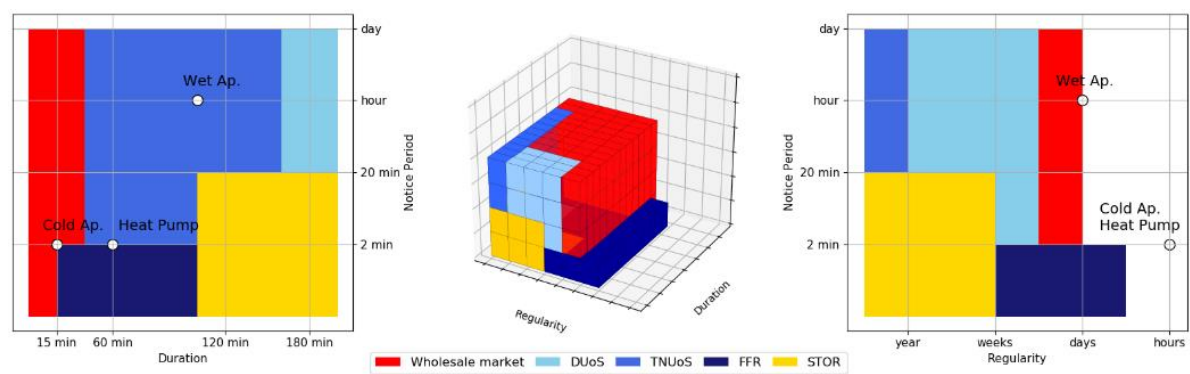

Fig. 3. DR framework

\subsection{Revenue evaluation}

Considering customer concerns for short-notice period and frequent DR requests, and observing the DR use selection framework (Fig. 3) manual DR programs seem to provide operational saving from the supplier's perspective. The flexibility capacity can be indicated as a percentage of the daily consumption [19] (Table 2), and it is remunerated in terms of energy shifted. Differently, in case of automated DR, flexibility is valued in terms of power. The temporal dimension (i.e. the synchrony between flexibility demand and its availability) was included in the methodology developed by Wegner et al. [19]. The flexible power $P_{k, j}$ is set as the average consumption of chosen appliances over the DR time window defined in [20,21] (Table 2), while the load flexibility share $c_{k, j}$ is defined as the fraction of power that can be actually shifted in time depending on DR use (minimum duration) and source (shiftability), see equation (2). For each DR use potential, revenues $R_{k, i}$ are evaluated as the product of the average power $P_{k, j}$, the temporal factor $c_{k, j}$ and the DR price $p_{D R, k}$, see equation (3)

$$
\begin{gathered}
c_{k, j}=\frac{\Delta t_{\text {flex }}}{\Delta t_{D R} \text { use }} \\
R_{k, i}=P_{k, j} \cdot c_{k, j} \cdot p_{D R, k}
\end{gathered}
$$

A remarkable aspect is the possibility to aggregate the flexibility sources in a portfolio for providing diverse services, according to economic and technical optimization strategies and to the needs of the energy system. As there is not a considerable literature evaluating the interaction of different DR sources and uses into a flexibility portfolio, the two extreme cases of perfect and absent integration and have been analysed.

The costs involved will vary significantly depending on the assets and the specific arrangement used to provide DR services. UK Power Networks [22] states that the main cost term is due managing customers relationship, accounting for $105[£ / y / p]$.

In Fig. 4., the analysis results are plotted at household level for the manual DR programs, while for the automated ones they are disaggregated by DR use and DR source. Finally, both the automated and manual DR programs revenues are compared to a reference operating cost [22]. In all scenarios the potential revenues are not sufficient to cover the high operational costs for running such programs. This occurs even in the best-case of perfect integration between different uses of demand flexibility. 

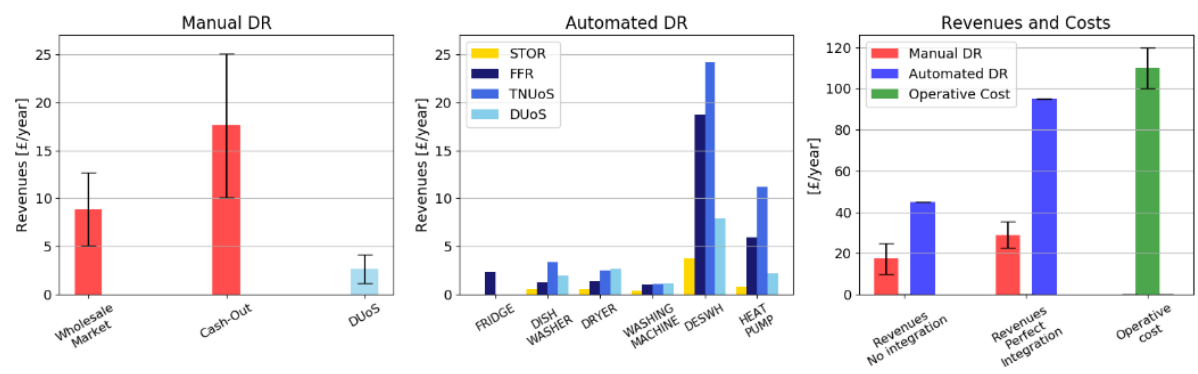

Fig. 4. DR programs revenues and cost estimations

\section{$5 \quad$ Discussion and Conclusions}

The present work addresses some of the challenges related to DR programs in the residential segment by investigating possible mechanisms and engagement strategies. However, the analysis is limited by several factors. The number of questionnaire respondents is too small to be statistically relevant and addressing a part of the population - namely elderly people - is challenging. This issue goes beyond the reach-out potential of a questionnaire tool, as it signals the scarce interest in such programs and the related technical barrier for a big part of the target customers. Spreading the questionnaire only through digital channels represented a technological barrier in itself, and this aspect may affect the development and the effectiveness of DR programs. For future applications, some adjustments should be made on the questionnaire. Openended questions should be avoided, and compulsory answers reduced in order to shorten it. To achieve a higher reliability of the WTP, respondents should state for each choice task whether they would actually purchase the preferred solution or not.

Moreover, each age cluster demonstrates different needs and drivers to participate in these initiatives. As the economic reward that can be returned to end-users results limited, it cannot be adopted as the main leverage to keep them involved and it is key to engage customers with various strategies. A way to reduce high drop-out rates is automating most of the process, so to require the least effort and time from customers. In addition, results from our preliminary economic assessment show that automated DR programs allow to realize higher revenues as the flexibility capacity can be used to provide more profitable services to the energy system.

This is likely to be the winning strategy in the long term to achieve a firm response that can be leveraged as a flexibility asset on electricity markets, but it requires a complete renovation of all appliances as they need to be "smart" and connected. This process started few years ago (and it is still going on) with respect to new energy efficiency labeling, therefore it is not likely to happen once again in the short term only relying on market mechanisms. In order to make this happen and to fully leverage the flexibility potential at household level, the relevant actors and stakeholders (suppliers, aggregators and system operators) must incentivize it properly so to create the conditions for DR programs to work. At this point, it should be considered whether the flexibility impact of household load shifting will be cannibalized by the de- 
ployment of storage systems and electric vehicles at scale. DR is not likely to substitute storage systems deployment but, if combined with them, it can reduce the overall costs for providing flexibility to the grid. The electrification of residential demands due to the diffusion of heat pumps and electric vehicles will open new scenarios for the role of Demand Response as a key flexibility asset of the power sector. Nevertheless, this solution must not be the reason to promote high electrification rates in the residential sector. It is meant for reducing stress and strains on the grid and its framework is the penetration of renewables.

\section{References}

1. Crosbie, T., Broderick, J., Short, M., Charlesworth, R., Dawood, M.: Demand Response Technology Readiness Levels for Energy Management in Blocks of Buildings. Buildings 8(2), 13 (2018).

2. Albadi, M.H., El-Saadany, E.F.: A Summary of Demand Response in Electricity Markets. Electric Power Systems Research 78(11), 1989-1996 (2008).

3. IEA: The Power to Choose: Demand Response in Liberalised Electricity Markets. OECD Publishing (2003).

4. Eid, C.: Demand Response in Europe's Electricity Sector: Market Barriers and Outstanding Issues. INIS 48(8), INIS-FR-17-0182 (2015).

5. Parrish, B., Heptonstall, P., Gross, R.: The Potential for UK Residential Demand Side Participation. HubNet, Tech. Rep. (2016).

6. Hledik, R., Gorman, W., Irwin, N., Fell, M., Nicolson, M., Huebner, G.: The Value of TOU Tariffs in Great Britain: Insights for Decision Makers. Citizen Advice, Final Report 1 (2017).

7. Chase, A., Gross, R., Heptonstall, P., Jansen, M., Kenefick, M., Parrish, B., Robson, P.: Realising the Potential of Demand-Side Response to 2025: A focus on Small Energy Users. Department for Business, Energy \& Industrial Strategy (UK), Sum. Report (2017).

8. Carmichael, R., Gross, R., Rhodes, A.: Unlocking the Potential of Residential Electricity Consumer Engagement with Demand Response, Energy Futures Lab (Imperial College London), Briefing Paper (2018).

9. Mangham-Jefferies, L., Hanson, K., Mcpake, B.: How to Do (or Not to Do) ... Designing a Discrete Choice Experiment for Application in a Low-income Country. Health Policy and Planning 24(2), 151-158 (2009).

10. Adamowicz, W., Boxall, P., Williams, M., Louviere, J.: Stated Preferences Approaches for Measuring Passive Use Values: Choice Experiments and Contingent Valuation. American Journal of Agricultural Economics 80(1): 64-75 (1998).

11. Pentland, A.: Social Physics: How Social Networks Can Make Us Smarter. Penguin Publishing Group (Kindle version), New York (2014).

12. Bottero, M., Cozza, G., Fontana, R., Monaco, R.: Choice Experiments: an Application for the Corona Verde Landscape in Turin (Italy). In Gervasi, O., et al. (eds.) Computational Science and Its Applications - ICCSA 2017. Lecture Notes in Computer Science, 10406, pp. 532-546. Springer, Cham (2017).

13. Haab, T.C., McConnell, K.E.: Valuing Environmental and Natural Resources: The Econometrics of Non-Market Valuation. Edward Elgar Publishing, Northampton (2002).

14. Frontier Economic, LCP, Sustainability First: Future potential for SDR in GB (2015).

15. McKenna, E., Thomson, M.: High-resolution Stochastic Integrated Thermal-electrical Domestic Demand Model. Applied Energy 165, 445-461 (2016). 
16. Carmichael, R., Schofield, J., Woolf, M., Bilton, M., Ozaki, R., Strbac, G.: Residential Consumer Attitudes to Time-varying Pricing. "Low Carbon London" LCNF project (Imperial College London), Tech. Rep. A2 (2014).

17. KEMA: 2005 Smart Thermostat Program Impact Evaluation prepared for San Diego Gas and Electric Company, California, US (2006).

18. Parrish B., Heptonstall, P., Gross R.: How Much Can We Really Expect from Smart Consumers?. HubNet, Position Paper (2015).

19. Wegner, M.S., Hall, S., Hardy, J., Workman, M.: Valuing Energy Futures; a Comparative Analysis of Value Pools Across UK Energy System Scenarios. Applied Energy 206, 815-828 (2017).

20. Hong, J., Kelly, N.J., Richardson, I., Thomson, M.: Assessing Heat Pumps as Flexible Load. Proceedings of the Institution of Mechanical Engineers, Part A: Journal of Power and Energy 227(1), 30-42 (2013).

21. Pagliuca, S., Lampropoulos, I., Bonicolini, M., Rawn, B., Gibescu, M., Kling, W.L.: Capacity Assessment of Residential Demand Response Mechanisms. 46 ${ }^{\text {th }}$ International Universities' Power Engineering Conference (UPEC), pp. 1-6, Soest, Germany (2011).

22. UK Power Networks: Industrial and Commercial Demand Response for Outage Management and as an Alternative to Network Reinforcement. "Low Carbon London" LCNF project, Tech. Rep. A4 (2014). 